\title{
Street-based adolescents at high risk of HIV in Ukraine
}

\author{
Joanna R Busza, ${ }^{1}$ Olga M Balakireva, ${ }^{2}$ Anja Teltschik, ${ }^{3}$ Tatiana V Bondar, ${ }^{4}$ \\ Yuliya V Sereda, ${ }^{4}$ Clea Meynell, ${ }^{5}$ Olena Sakovych ${ }^{6}$
}

${ }^{1}$ Centre for Population Studies, London School of Hygiene and Tropical Medicine, London, UK ${ }^{2}$ Ukrainian Institute for Social Research after Olexander Yaremenko, Kiev, Ukraine ${ }^{3}$ Independent consultant, Kiev, Ukraine

${ }^{4}$ Ukrainian Institute for Social Research after Olexander Yaremenko, Kiev, Ukraine ${ }^{5}$ Independent consultant, Kampala, Uganda ${ }^{6}$ UNICEF, Kiev, Ukraine

\section{Correspondence to}

Joanna R Busza, Centre for Population Studies, London School of Hygiene and Tropical Medicine, Keppel Street, London WC1E 7HT, UK; joanna.busza@lshtm.ac.uk

Accepted 31 May 2010 Published Online First 23 September 2010

\section{ABSTRACT}

Background Ukraine has the highest HIV prevalence in Europe, with young people disproportionately represented among populations at high risk. One particularly vulnerable group comprises adolescents who live or work on the streets. This study aimed to measure the extent and distribution of HIV risk behaviours among street-based adolescents in four Ukrainian cities as part of a regional UNICEF HIV prevention programme for most-at-risk adolescents.

Methods A cross-sectional behavioural survey was conducted of 805 adolescents (aged 10-19 years) in the cities of Kiev, Donetsk, Dnepropetrovsk and Nikolaev. Using location-based network and convenience sampling, 200 adolescents were reached in each site and were administered a standardised questionnaire on drug use, sexual behaviour, condom use, HIV knowledge, access to prevention services, experience of violence and contact with state institutions and police.

Results Considerable levels of HIV risk behaviour were found, including injecting drug use among $15.5 \%$ of the sample. Almost three-quarters of adolescents had experienced sexual debut, most before the age of 15 years. Male-to-male sexual behaviour was reported by just under $10 \%$ of boys. Condom use was low although varied by partner type. There were high rates of forced sex, and $75.5 \%$ of respondents reported police harassment.

Conclusions Street-based adolescents in Ukraine are at significant risk of contracting HIV due to involvement in injecting drug use and unprotected sex in personal and commercial exchanges, including male-to-male sex. This group initiates risk behaviours at early ages, and does not appear to have good access to prevention and other health services.

Following the collapse of the Soviet Union, Ukraine experienced many of the social and economic upheavals that have been implicated in the region's worsening population health, ${ }^{1}{ }^{2}$ including a rise in risk behaviours for HIV transmission. ${ }^{3}$ Ukraine now has the highest HIV prevalence in Europe, estimated at $1.63 \%$ of adults aged $15-49$ years. ${ }^{4}$ HIV remains concentrated among most-at-risk populations, namely injecting drug users (IDU), female sex workers (FSW) and men who have sex with men (MSM), but infection rates vary significantly between regions. 56

Adolescents are disproportionately represented among populations at risk; $19 \%$ of HIV infections occur among those aged 15-19 years. ${ }^{67}$ In the 2007 Behavioural Surveillance survey, adolescents aged 13-19 years comprised 6\% IDU, 18\% FSW and 12\% MSM (age $15+$ years). ${ }^{8-10}$ Studies from both Ukraine and other settings have shown that younger members of these populations engage in more risk behaviours than their older counterparts. ${ }^{711} 12$ The growing visibility of adolescents living without parental care in the region has led to increased concern for this group's vulnerability to HIV. ${ }^{13} 14$ The numbers of street-based adolescents in Ukraine are unavailable, although one estimate from 2003 put the figure at approximately $50000 .^{15}$ Nongovernmental organisation (NGO) and United Nations agency needs assessments suggest streetbased youth are a neglected risk group for HIV in Ukraine, ${ }^{16}$ particularly as a recent survey of over 300 street youth in St Petersburg, Russia, found 37.4\% HIV prevalence. ${ }^{17}$

Globally, homeless and street-based adolescents are particularly vulnerable and experience multiple adverse health outcomes, including high concentrations of HIV risk. ${ }^{18}{ }^{19}$ Studies have found associations with injecting drug use, ${ }^{20}$ exchange of sex for money, shelter, drugs and other goods, ${ }^{21} 22$ frequent sexual activity with a higher number of sexual partners than the general population of young people, ${ }^{23}$ low condom use in both personal and commercial sexual encounters ${ }^{21}$ and elevated exposure to physical and sexual violence, ${ }^{24}$ including by the police. ${ }^{25} 26$

This study aimed to measure the extent and distribution of HIV risk behaviours among streetbased adolescents aged 10-19 years in four Ukrainian cities, a group assumed to be at high risk despite the lack of any behavioural data or HIV/ sexually transmitted infection prevalence rates. This research formed part of UNICEF's first HIV prevention programme that explicitly defined and targeted most-at-risk adolescents. It was conducted in seven countries of East Europe with funding from Irish Aid. The programme's objectives were to increase the availability of data on at-risk adolescent populations, implement evidence-based interventions and evaluate their outcomes.

\section{METHODS}

We conducted a cross-sectional survey using a combination of location-based convenience and network sampling in the cities of Kiev, Donetsk, Dnepropetrovsk and Nikolaev. These sites were selected in order to reflect regional diversity, and because they had sizeable populations of street-based adolescents, links had been made to organisations interested in developing follow-up interventions, and local authorities were supportive of the research.

Key informants and local NGO assisted in mapping locations where street-based adolescents congregate. Formative research suggested they 
often cluster in small groups with an identified, frequently older, leader. Fieldworkers approached individuals or groups, introduced the research, and recruited eligible participants. Each respondent was asked to refer other members from his/her network and adolescents perceived to be group leaders were particularly encouraged to refer peers, especially those who might not be easily identified or frequent the same venues.

Interviews lasted between $30 \mathrm{~min}$ and an hour and took place on the street, or in a local café or NGO office, particularly during adverse weather conditions (data collection took place during early winter). Fieldworkers administered the questionnaire and took care to ensure as much privacy as possible; respondents were compensated with a 'gift pack' worth approximately US\$5 and containing a mix of personal items and snacks that varied by site (eg, shampoo, warm socks, juice box, piece of fruit, etc.)

We aimed to reach 200 youth in each city, including a target of 60 girls at each site to ensure adequate numbers to disaggregate the data by sex; this reflects available data suggesting a 2:1 male to female ratio among IDU and street youth in Ukraine. ${ }^{15}$ For purposes of this study, being 'street-based' was defined as spending at least $50 \%$ of the time on the streets and not attending school or being engaged in employment; respondents were eligible if they were aged 10-19 years, reported being 'on the streets' for at least 3 months, and if they appeared sober and capable of granting informed consent.

We used a standardised questionnaire developed for the UNICEF programme containing core modules on drug use, sexual behaviour, condom use, HIV knowledge and access to prevention services (NGO or state clinics, needle exchange programmes and outreach workers). Further sections were added on violence, institutionalisation in juvenile justice or social care facilities and interaction with police. The questionnaire was organised into 15 sections containing a maximum of 80 questions, although in reality most respondents answered far fewer due to screening questions and skip patterns. Questionnaires were translated into Russian and Ukrainian, pilot tested, and simplified for use by very young adolescents. Ethical approval was obtained from the Sociological Association of Ukraine. All analyses were conducted using STATA 10. $\chi^{2}$ tests were performed to assess the association between variables.

\section{RESULTS}

We recruited 805 adolescents. The median age for both sexes was 15 years and $81.5 \%$ were younger than 18 years and were thus minors under Ukrainian law. Most were Ukrainian, with a significant minority reporting Russian ethnicity. Less than a third $(28.5 \%)$ of under-18s were currently enrolled in school; educational attainment was low at every age. Although $41.4 \%$ of the sample reported living with a parent or other adult relative, $62.7 \%$ of boys and $43.8 \%$ of girls $(p<0.001)$ had been institutionalised within the care system at some point. Table 1 presents data on respondents' demographic background, social characteristics and behavioural risk profiles.

\section{Drug use}

Injecting drugs was reported by 125 respondents (15.5\%), the majority of whom initiated injecting between the ages of 14 and 16 years and now inject at least weekly. Among respondents who reported injecting drugs in the past month, most $(72.7 \%)$ stated they had used sterile injecting equipment the last time they injected, but close to half (44.1\%) shared needles at least once in the month before the interview.

Most obtain needles at the street-based locations where they inject with others (alleyways, stairwells, basements), with
Table 1 Characteristics of adolescents

Total

Demographic background

Sex

Male 565

Female $\quad 240$

Age, years

$10-14$

$15-17$

$18-19$

351

149

Ethnicity

Ukrainian

551

Russian

Other/I don't know

143

$111-13.8$

Living arrangement

$\begin{array}{lll}\text { Live with adult relatives } & 333 & 41.4\end{array}$

Live with friends

Ever institutionalised in care facility

419

52.0

Educational level

Never attended school

Up to full elementary

Up to basic secondary

Full secondary

Orphan status

Double orphan*

Single orphan

Not an orphan

Ever experienced police harassment

Ever been incarcerated in prison/juvenile detention

HIV risk and sexual health

Injecting drugs (ever use)

IDU injecting in the past month

IDU past month sharing needles/syringes

Ever had vaginal sex

Sex with a casual partner in past year

Condom use at last casual sex

Sex with a commercial partner in past year

Condom use at last commercial sex

Ever had anal sex between men (among boys)

Condom use at last MSM sex

Ever pregnant (among girls)

Ever had an abortion (among girls)

459

57.0

3.9

19.4

73.8

3.0

Use of services

IDU obtaining needles from pharmacy

IDU obtaining needles from needle exchange or outreach

Ever had an HIV test

Had HIV test in past year and know results

Ever received condoms from an outreach worker

$\begin{array}{rr}30 & 3.9 \\ 154 & 19.4 \\ 585 & 73.8 \\ 24 & 3.0\end{array}$

269

33.4

43.7

22.9

75.5

50.1

403

15.5

53.3

44.1

73.5

54.4

46.7

20.0

63.9

9.8

36.0

18.3

12.5

*Numbers may not add up to $100 \%$ when multiple responses or 'no answer' were options. IDU, injecting drug users; MSM, men who have sex with men.

$68.8 \%$ reporting receiving equipment from IDU friends. Approximately a quarter inject with a pre-filled syringe; other sources include sexual partners (26.4\%), picking used needles/ syringes up off the street (18.4\%) and theft (11.2\%). Only $8.9 \%$ have used a needles exchange programme in the past year; contact with outreach workers was reported by just seven individuals. Over half (55.2\%), however, are able to purchase clean needles from pharmacies.

\section{Sexual activity and condom use}

Overall, $73.5 \%$ of the sample reported ever having vaginal sex. There are notable variations by age and sex, with $42.9 \%$ of respondents aged 10-14 years reporting vaginal sex compared 
with all but two 18-19year olds. Among sexually active respondents, $76.1 \%$ experienced sexual debut before the age of 15 years and the rate of partner accumulation is high, with boys reporting a mean of 4.7 partners and girls 4.9 partners in the past 12 months. Two hundred and eight (26.3\%) respondents reported ever having anal sex, and 54 boys (9.8\%) reported anal sex with a man or boy (MSM). Among boys reporting MSM sex, the mean number of partners in the past year was 3.2.

Table 2 summarises some of the key gender differences in behaviour and exposure to HIV risk. Both boys and girls have exchanged sex for money, gifts or drugs, although the figure is higher among girls. The majority of girls who reported receiving a reward for sex did this for the first time between the ages of 12 and 16 years; however, reports of girls as young as 9 and 10 years old receiving rewards for sex were recorded.

Overall, 53.3\% of the sample reported unprotected sex at last intercourse with a casual partner. Young people obtain condoms from newsstands $(35.2 \%)$, pharmacies, shops or petrol stations $(31.9 \%)$ or friends $(28.9 \%)$. Almost half $(48.8 \%)$ of girls also get condoms from sexual partners, while only $29.7 \%$ of boys do so $(p<0.001)$. Girls exhibit better access to prevention services, with higher proportions both receiving condoms from outreach services and having ever had an HIV test. On the other hand, among sexually active girls, $18.3 \%$ have ever been pregnant and $68.2 \%$ of these obtained an abortion.

\section{Violence}

Among girls, overall $52.2 \%$ reported having ever experienced forced sex, among whom $70.9 \%$ had been forced in the past year. Although a significantly smaller proportion of boys reported forced sex, this figure rises to $49.0 \%$ among those reporting MSM behaviours.

Over 600 (75.5\%) respondents had been stopped or harassed by the police in the past, 328 of them over three times in the past year and 62 of them more than 21 times. Boys experienced police harassment and incarceration at significantly higher rates than girls.

\section{Overlapping risks}

There were clear associations between risk behaviours, particularly selling sex and injecting drugs. Among female IDU, 75.8\% also reported exchanging sex for money, gifts, or drugs; among boys the figure is $22.8 \%$. Among all the girls who have exchanged sex, $18.4 \%$ also inject drugs. Of the 54 boys reporting MSM, 16 were also IDU (29.6\%).

Table 2 Gender differences in vulnerability

\begin{tabular}{|c|c|c|c|c|c|}
\hline & \multicolumn{2}{|c|}{ Male } & \multicolumn{2}{|c|}{ Female } & \multirow[b]{2}{*}{ p Value } \\
\hline & $\mathrm{n}$ & $\%$ & $\bar{n}$ & $\%$ & \\
\hline \multicolumn{6}{|l|}{ Risk behaviours } \\
\hline Ever had vaginal sex & 389 & 69.7 & 196 & 82.4 & $<0.001$ \\
\hline Ever received payment/gift for sex & 93 & 16.5 & 136 & 56.7 & $<0.001$ \\
\hline Unprotected sex at last casual sex & 136 & 54.4 & 48 & 50.5 & 0.520 \\
\hline $\begin{array}{l}\text { Unprotected sex at last commercial sex } \\
\text { (MSM and FSW) }\end{array}$ & 12 & 57.1 & 34 & 35.8 & 0.070 \\
\hline Ever injected drugs & 92 & 16.3 & 33 & 13.8 & 0.364 \\
\hline \multicolumn{6}{|l|}{ Service use } \\
\hline Receive condoms from outreach & 7 & 1.2 & 33 & 13.8 & $<0.001$ \\
\hline Ever had an HIV test & 113 & 20.0 & 66 & 27.7 & 0.019 \\
\hline \multicolumn{6}{|l|}{ Violence } \\
\hline Ever forced to have sex & 60 & 11.2 & 107 & 52.2 & $<0.001$ \\
\hline Ever stopped or harassed by police & 468 & 82.8 & 140 & 58.3 & $<0.001$ \\
\hline
\end{tabular}

FSW, female sex worker; MSM, men who have sex with men.

\section{Knowledge of HIV}

We assessed knowledge of HIV through the five-question scale used to compile UNGASS indicators for young people and mostat-risk populations, as well as additional knowledge questions specific to IDU transmission. ${ }^{27}$ Overall, $13.3 \%$ respondents correctly identified ways of preventing sexual transmission of HIV and rejected major misconceptions, with significant differences between boys $(11.7 \%)$ and girls $(17.1 \% ; p<0.05)$. The low knowledge scores are mainly due to the prevalence of misconceptions; fewer than half knew that HIV could not be spread through mosquito bites (41.4\%), or sharing crockery $(37.4 \%)$. The majority of both boys and girls knew that using condoms at each sex act reduced HIV risk (63.5\%), and that using clean injecting equipment did so $(61.2 \%)$. The subsample of IDU demonstrated slightly better levels of knowledge, with $68.8 \%$ replying correctly that HIV could be prevented through the use of clean, unused needles and $75.2 \%$ by consistent condom use.

\section{DISCUSSION}

This cross-sectional survey of 805 street-based adolescents in four Ukrainian cities found high levels of HIV risk-related behaviours, particularly for sexual transmission. Three-quarters of respondents were sexually active, including $42.9 \%$ of the youngest age group. Sexual debut occurred before the age of 15 years for most, a frequently used indicator of elevated social and biological vulnerability. ${ }^{28}$

A range of different types of sexual partners was reported. The majority of girls $(56.7 \%)$ and $16.5 \%$ of boys reported receiving money, gifts or drugs in exchange for sex, and $7.4 \%$ of boys reported paying for sex. Condom use is inconsistent. As expected, condoms were most likely to be used during commercial sex and less so with casual or steady partners, in which a personal relationship may be established. ${ }^{29}{ }^{30}$ For MSM, condom use at last sex was low at between 36\% and 39\% for all partner categories. Low condom use probably reflects the disempowered status of adolescents vis-à-vis adult sexual partners; on the other hand, that condom use was reported at all suggests street-based youth are motivated to protect themselves from HIV, other sexually transmitted infections, and/or pregnancy, perhaps particularly during sexual relationships with other young people. As few respondents received condoms free of charge from services, but rather purchased them from pharmacies or other outlets, there is clear scope for improving condom availability for this group. The availability of other means of contraception should also be prioritised to address the high rate of unwanted pregnancies among street-based girls.

Although a minority of this sample inject drugs, they nonetheless exhibit a higher rate of injecting than many other streetbased adolescent populations for whom the cost of heroin proves prohibitive, ${ }^{31}$ although studies in the USA have found even higher rates among homeless youth. ${ }^{32}$ In Ukraine, however, IDU inject locally or home-produced substances, including poppy straw extract, cooked amphetamines and, as recently reported, methcathinone made from cold medications containing phenylpropanolamine, referred to as 'boltushka'. ${ }^{33}$ In our study, most IDU reported sharing injecting equipment in the past month and did not access harm-reduction services. Just 11 ever visited a needle exchange, and almost none received needles from an outreach worker. Injecting drug use was also associated with other risk behaviours, including more frequent commercial sex. Knowledge levels seemed fairly low, although most knew that using condoms and clean injecting equipment were effective prevention measures. 
Our results highlight the disturbing reality of regular violence, including by police. Nearly half of female respondents experienced forced sex and MSM were also at higher risk of sexual assault. Rather than providing protection, the police are perceived to pose an additional threat, as over three-quarters of the sample reported ever having been stopped or harassed; boys appear particularly vulnerable. This resonates with findings from both Brazil and Egypt, where street children are often explicitly targeted by authorities. ${ }^{25} 26$ Addressing HIV is unlikely to have any real effect until basic human rights are assured for street-based adolescents, as high levels of harassment make it unlikely they will trust authorities tasked with their care.

\section{CONCLUSION}

This research is among the first behavioural study conducted among most-at-risk adolescents in the region and clearly demonstrates that street-based adolescents in Ukraine are at significant risk of contracting HIV due to involvement in injecting drug use and unprotected sex in personal and commercial exchanges, including male-to-male sex. This group initiates risk behaviours at early ages, and does not appear to have good access to prevention and other health services. Since the completion of this study, a national HIV prevalence study among 15-24 year olds living or working on the street found $18.4 \%$ infection rates, further confirming the extreme vulnerability of the adolescents in this group. ${ }^{34}$

Careful design of appropriate services to increase contact and trust of street-based youth are imperative to provide them with harm reduction and child protection. Further research to explore which facilities are perceived as convenient and 'user friendly' by street-based adolescents should guide future programming. It

\section{What is already known on this subject}

Children and adolescents who live or work on the streets are recognised as a marginalised group, and studies from numerous contexts have identified elevated rates of drug-taking and sexual risk among them. In Ukraine, which has the highest HIV prevalence in Europe, large populations of street-based young people have become increasingly visible in urban areas, although no behavioural data were available on the prevalence and distribution of HIV risk.

\section{What this study adds}

This is the first study to examine patterns of high-risk activity among adolescents aged $10-19$ years who spend at least $50 \%$ of their time on the street in four Ukrainian cities. The results confirm that this population is extremely vulnerable to HIV due to a range of overlapping risk behaviours including casual and transactional sex, poor condom use and injecting drug use, as well as wider structural factors such as high rates of sexual violence, distrust of social services and other authorities, and harassment from the police, all of which restrict street-based adolescents' ability to protect themselves or access harmreduction or treatment services. Effective HIV or health programmes targeting this group will need to address the wider risk environment that characterises life on the street. may be possible to build on 'entry points' identified by this research, such as IDUs' willingness to buy needles/syringes from pharmacies, and the fact that over $20 \%$ of the sample has ever tested for HIV. Similarly, the discovery of a fairly high rate of pregnancy among girls could also serve as an opportunity to reach some street-based adolescents, not only for reproductive and maternal health services, but as a means to establish positive contact. Programmes in other settings have found that girls who usually do not attend clinical services are more amenable to health-seeking during pregnancy, which can be used as a means to introduce other health promotion activities ${ }^{35}$ or even assist girls in re-evaluating their life choices. ${ }^{36}$

The fact that many street-based adolescents retain relationships with their families might also provide intervention possibilities. Other studies have found that homeless youth are at greater risk than those who sleep at home, ${ }^{37} 38$ and it has been suggested that assessment of the family situation and targeted support activities could help reduce vulnerability of some individuals. ${ }^{39}$ It is difficult to envision successful interventions for this group of vulnerable young people, however, without the high rates of harassment by police and forced institutionalisation in social facilities first being addressed. A similar study of street-based children conducted in Sudan concluded that policy change was a pre-condition for further positive action, and efforts to enact protective legislation and initiate police training led to a more favourable environment for subsequent educational and preventive programmes. ${ }^{40}$ Concerted advocacy efforts within Ukraine and beyond should emphasise the damaging role played by abuse perpetuated by authorities, particularly as these same authorities have a mandate for public protection.

Acknowledgements The authors would like to thank the UNICEF Regional Office for Central and Eastern Europe/Commonwealth of Independent States for supporting this research, and Irish Aid for providing funding. Further thanks go to Megan Douthwaite for assistance with data analysis. They are also extremely grateful to all the young people who participated in this research.

Funding This study was supported by UNICEF with funding from Irish Aid.

\section{Competing interests None declared}

Ethics approval This study was conducted with the approval of the Sociological Association of Ukraine.

Contributors JRB assisted in the study and provided support during fieldwork and analysis, and draftedthe first version of the paper. OMB served as principal investigator throughout the research. AT provided technical assistance and coordinated stages of the research. TVB and YVS conducted statistical analysis and contributed to drafting subsequent versions of the paper. CM undertook additional statistical analysis. OS helped design and coordinate the research.

Provenance and peer review Not commissioned; externally peer reviewed.

\section{REFERENCES}

1. Cockerham WC, Hinote BP, Abbott P. Psychological distress, gender, and health lifestyles in Belarus, Kazakhstan, Russia, and Ukraine. Soc Sci Med 2006:63:2381-94.

2. Feachem R. Health decline in Eastern Europe. Nature 1994;367:313-14.

3. DeBell D, Carter R. Impact of transition on public health in Ukraine: case study of the HIV/AIDS epidemic. BMJ 2005;331:216-19.

4. Kruglov YV, Kobyshcha YV, Salyuk T, et al. The most severe HIV epidemic in Europe: Ukraine's national HIV prevalence estimates for 2007. Sex Transm Infect 2008;84: i37-41.

5. Atlani L, Caraël M, Brunet JB, et al. Social change and HIV in the former USSR: the making of a new epidemic. Soc Sci Med 2000:50:1547-56.

6. Kelly JA, Amirkhanian YA. The newest epidemic: a review of HIV/AIDS in Central and Eastern Europe. Int J STD AIDS 2003;14:361-71

7. European Collaborative Study. HIV-infected pregnant adolescents and youth: results from a European cohort study. Vulnerable Child Youth Stud 2006;1:195-204.

8. Balakireva OM, Bondar T, Sereda Y. Behavioral monitoring of commercial sex workers as a component of second generation surveillance: analytical report on research results [in Ukrainian]. Kiev: International HIV/AIDS Alliance Ukraine, 2008.

9. Balakireva OM, Bondar T, Sereda Y. Behavioral monitoring of injection drug users as a component of second generation surveillance: analytical report on research results [in Ukrainian]. Kiev: International HIV/AIDS Alliance Ukraine, 2008. 
10. Balakireva OM, Bondar T, Sereda Y. Behavioral monitoring of men having sex with men as a component of second generation surveillance: analytical report on research results [in Ukrainian]. Kiev: International HIV/AIDS Alliance, 2008.

11. Fennema JSA, Ameijden EJCV, Hoek AVD, et al. Young and recent-onset injecting drug users are at higher risk for HIV. Addiction 1997;92:1457-66.

12. Kral AH, Lorvick J, Edlin BR. Sex-and drug-related risk among populations of younger and older injection drug users in adjacent neighborhoods in San Francisco. J Acquir Immune Defic Syndr 2000;24:162-7.

13. Athey JL. HIV infection and homeless adolescents. Child Welfare 1991:70:517-28.

14. Goodwin R, Kozlova A, Nizharadze G, et al. HIV/AIDS among adolescents in Eastern Europe: knowledge of HIV/AIDS, Social representations of risk and sexual activity among school children and homeless adolescents in Russia, Georgia and the Ukraine. $\mathrm{J}$ Health Psychol 2004;9:381-96.

15. Kerfoot M, Koshyl V, Roganov O, et al. The health and well-being of neglected, abused and exploited children: the Kyiv Street Children Project. Child Abuse Negl 2007;31:27-37.

16. Teltschik A. Children and young people living of working on the streets: the missing face of the HIV epidemic in Ukaine. Kiev: UNICEF, 2006.

17. Kissin DM, Zapata L, Yorick R, et al. HIV seroprevalence in street youth, St Petersburg, Russia. AIDS 2007:21:2333-40.

18. Krakauer M, Newbery J. Churches' responses to HIV/AIDS in two South African communities. J Int Assoc Physicians AIDS Care (Chic, III) 2007;6:27-35.

19. Marshall B, Kerr T, Shoveller J, et al. Structural factors associated with an increased risk of HIV and sexually transmitted infection transmission among streetinvolved youth. BMC Public Health 2009;9:7.

20. Weber AE, Boivin JF, Blais L, et al. High risk profile and prostitution among female street youths. J Urban Health 2002;79:525-35.

21. Haley N, Roy E, Leclerc $P$, et al. HIV risk profile of male street youth involved in survival sex. Sex Transm Infect 2004;80:526-30.

22. Towe VL, ul Hasan S, Zafar ST, et al. Street life and drug risk behaviors associated with exchanging sex among male street children in Lahore, Pakistan. J Adolesc Health 2009; 44:222-8.

23. Walters AS. HIV prevention in street youth. J Adolesc Health 1999;25:187-98.

24. Kipke MD, Simon TR, Montgomery SB, et al. Homeless youth and their exposure to and involvement in violence whle living on the streets. J Adolesc Health 1997;20:360-7.

25. Human Rights Watch. Charged with being children: Egyptian police abuse of children in need of protection. London: Human Rights Watch, 2003.
26. Ribeiro Mo. Street children and their relationship with the police. Int Nurs Rev 2008;55:89-96.

27. UNAIDS. Monitoring the declaration of commitment on HIVIAIDS: guidelines on construction of core indicators. Geneva: UNAIDS, 2009:53.

28. Wellings K, Collumbien M, Slaymaker E, et al. Sexual behaviour in context: a global perspective. Lancet 2006:368:1706-28.

29. Sopheab H, Morineau G, Neal J, et al. Sustained high prevalence of sexually transmitted infections among female sex workers in Cambodia: high turnover seriously challenges the $100 \%$ condom use programme. BMC Infect Dis 2008:8:167.

30. Voeten HACM, Egesah $\mathrm{OB}$, Varkevisser CM, et al. Female sex workers and unsafe sex in urban and rural Nyanza, Kenya: regular partners may contribute more to HIV transmission than clients. Trop Med Int Health 2007;12:174-82.

31. Torres de Carvalho F, Neiva-Silva L, Ramos MC, et al. Sexual and drug use risk behaviors among children and youth in street circumstances in Porto Alegre, Brazil. AIDS Behav 2006:10:57-66.

32. Clements K, Gleghorn A, Garcia D, et al. A risk profile of street youth in Northern California: Implications for gender-specific human immunodeficiency virus prevention. $J$ Adolesc Health 1997;20:343-53.

33. Repsina CD, Case P, Kitsenko N, et al. Boltushka: a homemade amphetamine-type stimulant and HIV risk in Odessa, Ukraine. Int J Drug Policy 2009:20:347-51.

34. Shevchenko N, Robbins C, Zapata L, et al. HIV prevalence among street youth in several cities in Ukraine [in Russian]. Abstract presented at the IIIrd Eastern European and Central Asian AIDS Conference; Moscow, 28-30 October 2009. Abstract book 1:177-8

35. Hathazi D, Lankenau SE, Sanders B, et al. Pregnancy and sexual health among homeless young injection drug users. J Adolesc 2009:32:339-55.

36. King AU, Ross LE, Bruno TL, et al. Identity work among street-involved young mothers. J Youth Studies 2009:12:139-49.

37. Lambert ML, Torrico F, Billot C, et al. Street youths are the only high-risk group for HIV in a low-prevalence South American country. Sex Transm Dis 2005;32:240-2.

38. Moon M, Binson D. Page-Shafer $\mathrm{K}$, et al. Correlates of HIV risk in a random sample of street youth in San Francisco. J Assoc Nurses AIDS Care 2001;12:18-27.

39. Morakinyo J, Odejide AO. A community based study of patterns of psychoactive substance use among street children in a local government area of Nigeria. Drug Alcohol Depend 2003;71:109-16.

40. Kudrati M, Plummer ML, Yousif ND. Children of the sug: a study of the daily lives of street children in Khartoum, Sudan, with intervention recommendations. Child Abuse Negl 2008;32:439-48. 